\title{
A comparative study of oral nifedipine and intravenous labetalol in control of acute hypertension in severe pre-eclampsia and eclampsia
}

\author{
Yogita Gavit*, Deepika Sharma, Pratibha V. Dixit
}

Department of Obstetrics and Gynecology, Government Medical College, Aurangabad, Maharashtra, India

Received: 15 December 2017

Accepted: 08 January 2018

*Correspondence:

Dr. Yogita Gavit,

E-mail: dryogita1990@gmail.com

Copyright: (C) the author(s), publisher and licensee Medip Academy. This is an open-access article distributed under the terms of the Creative Commons Attribution Non-Commercial License, which permits unrestricted non-commercial use, distribution, and reproduction in any medium, provided the original work is properly cited.

\begin{abstract}
Background: This study was conducted to compare oral Nifedipine and intravenous Labetalol in control of acute hypertension in severe pre-eclampsia and eclampsia. This study was observational study with 80 sample size in which 40 sample size treated with intravenous Labetalol and other 40 sample size treated with oral Nifedipine. The maternal and perinatal outcome in two groups sample size with oral Nifedipine and intravenous Labetalol compared and found that nevertheless these results do establish oral Nifedipine as an alternative to IV Labetalol in lowering BP in acute severe hypertension. In summary oral Nifedipine may be preferable as it has a convenient dosing pattern orally.

Methods: The present study was conducted in tertiary care centre Mumbai from June 2016 to October 2016. All pregnant woman diagnosed with acute hypertension in severe pre-eclampsia and eclampsia in labour room were enrolled in the study.

Results: In the present study oral Nifedipine as an alternative to IV Labetalol in lowering BP in acute severe hypertension. In summary oral Nifedipine may be preferable as it has a convenient dosing pattern orally.

Conclusions: A hypertensive disorder of pregnancy is one of the life-threatening complication encountered in obstetrics and globally is major cause of maternal morbidity and mortality. Management of acute severe hypertension in pregnancy is a challenging task. Present study compares the efficacy of oral Nifedipine and IV Labetalol in reaching the therapeutic goal. From the results of this study we can well conclude that oral Nifedipine is more efficacious.
\end{abstract}

Keywords: Eclampsia, Intravenous labetalol, Oral nifedipine, Severe pre-eclampsia

\section{INTRODUCTION}

Hypertensive disorders of pregnancy are the common medical disorders in pregnancy. It has effects both on expectant mother and fetus. ${ }^{1-3}$ The impact due to hypertensive disorders in pregnancy on maternal and neonatal mortality and morbidity is very high in India and other developing countries. ${ }^{4,5}$ The incidence of pregnancy induced hypertension in India is about $10 \%$ of all antenatal admission. ${ }^{6}$ Severe forms of hypertensive disorders of pregnancy like eclampsia is a major cause of maternal mortality. ${ }^{7-9}$ Pre-eclampsia is a disease of multiple organ system that is unique to pregnancy can cause maternal complications like Eclampsia, HELLP syndrome, acute renal failure, cerebrovascular accidents etc. It has effect on the fetus like fetal growth restriction, oligohydramnios, and fetal distress. During pregnancy the priority regarding hypertension is in making the correct diagnosis as to distinguish pre-existing (chronic) from pre-eclampsia or gestational hypertension. Then is to distinguish blood pressure levels as either mild (140/90 to $159 / 109 \mathrm{~mm}$ of $\mathrm{Hg})$ or severe $(\geq 160 / 110 \mathrm{~mm}$ of $\mathrm{Hg})$ rather than as stages. The management of pregnancy induced hypertension is aimed at termination of pregnancy, but this cannot be done in all cases, as most cases are preterm or very preterm. The pregnancy can be prolonged by using antihypertensive 
agents by till a period where in fetal survival is good, there by maximizing the gestational age of fetus and minimizing the fetal exposure to medication that may have adverse effects. The focus of treatment is the 9 months of pregnancy during which, untreated mild to moderate hypertension generally have maternal and fetal outcome as comparable to normotensive women.

In this regard antihypertensive agents are mainly used to prevent and treat severe hypertension. The antihypertensive agents have a role in controlling hypertension and there by maternal and fetal complications can be avoided. ${ }^{1-3}$ The commonly used antihypertensive drugs in pregnancy induced hypertension are Methyldopa, Labetalol, other beta blockers (Acebutolol, Metoprolol, Pindolol and Propranolol) and calcium channel blockers Nifedipine. There are few studies evaluating the efficacy of antihypertensive agents in pregnancy. The efficacy of the drug in controlling the high blood pressure is important in preventing complications both to women and fetus. ${ }^{2}$

At the same time the adverse effect of antihypertensive agents on mother and fetus is also important. The effects of maternal antihypertensive drug use during pregnancy on fetal growth and wellbeing remains uncertain. Metaanalysis of randomized clinical trials has highlighted the possible association between antihypertensive therapy and both intrauterine growth restriction (IUGR) and small for gestational age (SGA) birth weight. Multiple drug therapy had the strongest association with these events. ${ }^{4}$ Gestational use of antihypertensive, especially betablockers, alpha beta blockers, or centrally acting adrenergic agents may increase the risk of SGA births. ${ }^{5}$

The most commonly used hypertensive agents for hypertensive emergencies in pregnancy are Nifedipine, Labetalol and Hydralazine. Nifedipine has the advantage of being cost effective, rapid onset of action, long duration of action and can be administered orally, however it is known to cause sudden maternal hypotension and fetal distress caused by placental hypo perfusion, palpitation and transient neuromuscular weakness when used concomitant with magnesium sulphate. Intravenous Labetalol is considered to control severe hypertension in pregnancy. Its advantages include little placental transfer, less palpitation and less maternal tachycardia, however neonatal hypotension and neonatal bradycardia has been observed in some trials and is not as cost effective as Nifedipine.

In India, Nifedipine is the most commonly used antihypertensive for blood pressure control in severe hypertension because of its easy availability, rapid onset of action, ease of oral administration and satisfactory reduction in blood pressure. An interaction between Nifedipine and Magnesium Sulphate may be associated with profound muscle weakness and hypotension. Nifedipine and Magnesium Sulphate both have tocolytic effect and can prolong the duration of labour.

\section{METHODS}

The present study was conducted in a tertiary care centre Mumbai from June 2015 to October 2016 after takin permission from institutional ethical committee. Cases were enrolled till June 2016 and the last case was followed up till October 2016.

\section{Inclusion criteria}

Patients with preeclampsia/eclampsia and $\mathrm{BP} \geq 140 / 90 \mathrm{~mm}$ $\mathrm{Hg}$ and the gestational age $>34$ weeks upto 41 weeks.

\section{Exclusion criteria}

- Patients with essential hypertension.

- H/O Cardiac disease.

- H/O Bronchial asthma.

- H/O Hematological disorder.

- H/O Allergy to Labetalol or Nifedipine

- Diabetic

- Liver disorders

- Maternal heart rate $<60$ or $>120$ beats per minute

\section{Antihypertensive drugs used in the study}

- Labetalol Injection: Lobet - 20mg, (Samarth Pharma Pvt Ltd).

- Nifedipine Capsules: Depin-10 mg, (Zydus Cadila).

\section{Sampling method}

All the patients were in-patients. Ethical clearance from the Institutional. Human Ethics committee of Lokmanya Tilak Municipal Medical College and Hospital, Sion, Mumbai was taken for the study. General consent was taken for administration of all drugs as deemed necessary for management. Each participant's hospital identification number was recorded at the time of presentation, and mothers and infants' data were subsequently abstracted from their hospital charts and entered into standard data collection form (Proforma) designed for the study (Annexure).

No financial assistance taken from Samarth Pharma Pvt Ltd and Zydus Cadila for this study.

Preterm or term pregnant women with severe preeclampsia/ eclampsia and $\mathrm{BP} \geq 160 / 100 \mathrm{~mm} \mathrm{Hg}$ to be recruited, Patients were randomly assigned to be started either with intravenous Labetalol (Study Group) or oral Nifedipine (Control Group) until satisfactory BP control is achieved that is $<140 / 90 \mathrm{~mm} \mathrm{Hg}$.

(Group A): Injection Labetalol $20 \mathrm{mg} \mathrm{I} \mathrm{V} \mathrm{bolus} \mathrm{over} 10$ minutes repeated every 20 -minutes increasing dosage to $40 \mathrm{mg}, 80 \mathrm{mg}$, repeat dosage by $80 \mathrm{mg}$ to a maximum of $300 \mathrm{mg}$ can be given. ${ }^{10-13}$ 
(Group B): Oral Nifedipine $10 \mathrm{mg}$ stat and then repeated as $5 \mathrm{mg}$ dosage maximum upto 50mg at 20 minutes interval till satisfactory BP control is achieved. Maximum dose of oral Nifedipine can be given is 5 doses that is upto $50 \mathrm{mg}$ in dosage form. ${ }^{10-12}$

During the study period maternal blood pressure will be recorded at every fifteen minutes interval till first 30 minutes after achieving target blood pressure equal to or less than 140/90 mmhg, then every 30 minutes for next 2 hours followed by hourly for next 24 hours. Continuous maternal vital parameters and fetal heart sounds via fetal Doppler will taken at the beginning and after every 30 minutes after achieving target blood pressure equal to or less than 140/90 mmh. Selected patients will be analyzed and comparison between the Group A and Group B will be carried out.

Treatment will be considered as failure if blood pressure does not decrease even after increasing the dosage to maximum. Additional antihypertensive agent will be added and managed accordingly. If patient develops hypotension BP less than 90/60 mm hg then the trial will be terminated and patient treated with intravenous fluids and ephedrine. If bradycardia develops pulse less than 60 beat/min then the trial will be terminated, and patient treated with atropine.

\section{RESULTS}

When age distribution of PIH patients were analysed, maximum number of patients were 25 to 30 years of age followed by 19 to 24 years and > 30 years respectively in the descending order. Above analysis for age distribution in both groups found no significance. The mean age in our study was 26.10 years. In following studies conducted the maternal mean age in both the group in Shekhar et al was 25.9 years, Swapan et al was 25.4 years while in Raheem et al was 31.4 years as the distribution of age was from 20 to 40 years, and sample size was less $(n=50)$ (Table 1). ${ }^{14-16}$

Table 1: Comparison of age distribution of the two groups.

\begin{tabular}{|c|c|c|c|c|c|}
\hline \multirow{2}{*}{ Age } & \multicolumn{2}{|c|}{ IV Labetalol } & \multicolumn{3}{|c|}{ Oral Nifedipine } \\
\hline & No & $\%$ & No & $\%$ & \multirow{5}{*}{$P=0.329$} \\
\hline $19-24$ & 19 & 47.5 & 18 & 45 & \\
\hline $25-30$ & 15 & 37.5 & 16 & 40 & \\
\hline$>30$ & 6 & 15 & 6 & 15 & \\
\hline Total & 40 & 100 & 40 & 100 & \\
\hline
\end{tabular}

Table 2 shows the Gravida distribution of patients studied in each group with a range of primigravida to 4 th gravid. Maximum patients of severe pre-eclampsia were primigravida and second gravida in both the groups. The table analysis above mentioned states that high incidence of pre-eclampsia found in primigravida. In other studies carried out the maximum patients of severe pre-eclampsia were primigravida Raheem et al 36 out of 50 patients were
Primigravida, Shekhar et al 58 out of 60 patients were Primigravida, Swapan et al 49 out of 100 patients were Primigravida. ${ }^{14-16}$

Table 2: Gravida distribution of the two groups.

\begin{tabular}{|c|c|c|c|c|c|}
\hline \multirow{2}{*}{ Gravida } & \multicolumn{2}{|c|}{ IV Labetalol } & \multicolumn{3}{|c|}{ Oral Nifedipine } \\
\hline & No & $\%$ & No. & $\%$ & \multirow{6}{*}{$\mathrm{P}=0.574$} \\
\hline Primi & 17 & 42.5 & 18 & 45 & \\
\hline $\mathrm{G} 2$ & 14 & 35 & 14 & 35 & \\
\hline G3 & 8 & 20 & 7 & 17.5 & \\
\hline G4 & 1 & 2.5 & 1 & 2.5 & \\
\hline Total & 40 & 100 & 40 & 100 & \\
\hline
\end{tabular}

Table 3 shows the gestational age at presentation in each group. Most patients with pre-eclampsia belonged to 38 39 weeks of gestational age $57.5 \%$ in the Labetalol group and $50 \%$ in the Nifedipine group, followed by 37-38 weeks. The analysis derived states that severe preeclampsia incidence in this study for IV Labetalol is between 38-39 weeks gestation and for oral Nifedipine is 37-38 weeks while the comparison between two is not significant. The result found in other studies was Raheem et al, Shekhar et al, Swapan et al shows period of gestation in IV Labetalol and Oral Nifedipine are 36.3-38.6 and 3538.6, 36-38 and 37-38, 38-40 and 38-40 weeks respectively. Hence Severe Pre-eclampsia condition often seen in late trimester of pregnancy. ${ }^{14-16}$

Table 3: Comparison of gestational age of the two groups.

\begin{tabular}{|c|c|c|c|c|c|}
\hline \multirow{2}{*}{ GA (weeks) } & \multicolumn{2}{|c|}{ IV Labetalol } & \multicolumn{3}{|c|}{ Oral Nifedipine } \\
\hline & No. & $\%$ & No. & $\%$ & \multirow{6}{*}{$\mathrm{P}=0.325$} \\
\hline $36.1-37$ & 2 & 5 & 2 & 5 & \\
\hline $37.1-38$ & 13 & 32.5 & 16 & 40 & \\
\hline $38.1-39$ & 23 & 57.5 & 20 & 50 & \\
\hline$>39$ & 2 & 5 & 2 & 5 & \\
\hline Total & 40 & 100 & 40 & 100 & \\
\hline
\end{tabular}

Table 4: Comparison between systolic and diastolic BP of the two groups.

\begin{tabular}{|c|c|c|c|}
\hline Variables & $\begin{array}{l}\text { IV Labetolol } \\
(\mathrm{n}=40) \\
\text { Mean } \pm \text { SD }\end{array}$ & $\begin{array}{l}\text { Oral } \\
\text { Nifedepine } \\
(\mathrm{n}=40) \\
\text { Mean } \pm \text { SD }\end{array}$ & $\begin{array}{l}\mathbf{P} \\
\text { value }\end{array}$ \\
\hline $\begin{array}{l}\text { Systolic BP } \\
\text { (mm of Hg) }\end{array}$ & $176.05 \pm 12.87$ & $171.75 \pm 12.45$ & 0.133 \\
\hline $\begin{array}{l}\text { Diastolic BP } \\
\text { (mm of } \mathrm{Hg} \text { ) }\end{array}$ & $112.35 \pm 5.10$ & $112.85 \pm 5.29$ & 0.668 \\
\hline
\end{tabular}

Table 4 Shows comparison of systolic and diastolic BP of the two groups. Mean SBP was176.05 $\pm 12.87 \mathrm{~mm}$ of $\mathrm{Hg}$ in the IV Labetalol group and $171.75 \pm 12.45 \mathrm{~mm}$ of $\mathrm{Hg}$ in the Oral Nifedipine group, which was statically not significant as ' $\mathrm{P}$ ' value was 0.133. Mean diastolic BP was $112.35 \pm 5.10 \mathrm{~mm}$ of $\mathrm{Hg}$ in the Labetalol group and $112.85 \pm 5.29 \mathrm{mmHg}$ in the Nifedipine group which was 
also statistically insignificant and ' $P$ value was 0.668 respectively.

The above mean blood pressure at first visit in my study is comparable with the studies of Raheem et al where mean blood pressure at first visit was $170 / 108 \mathrm{~mm} \mathrm{hg}$ in IV Labetalol and 175/110 mmhg in Oral Nifedipine group, Shekhar et al mean blood pressure at first visit was 168110 $7.8 \mathrm{mmhg}$ in IV Labetalol and 165/108 mmg in Oral Nifedipine group, Swapan et al mean blood pressure at first visit was $186.28 \mathrm{mmhg}$ in IV Labetalol and 1758 mmhg in Oral Nifedipine group. No bias selection of patients in both the groups. ${ }^{14,15}$

Table 5 shows comparison of No. of doses of drugs required to control BP between two groups. Most of the patients were controlled by two doses of each drug, $75 \%$ in the Labetalol group and $95 \%$ in the Nifedipine group. While no. of doses required to control blood pressure in severe pre-eclampsia in other studies Raheem et al and Shekhar et al was 3 doses in IV Labetalol group and 2 doses in Oral Nifedipine group, Swapan et al 2 doses n IV Labetalol and oral Nifedipine group. ${ }^{15,16}$ Thereby oral Nifedipine requires less number of doses to control raised blood pressure in Pre-eclampsia/eclampsia.

Table 5: Comparison of no. of doses of drugs required to control BP between two groups.

\begin{tabular}{|l|llll|}
\hline \multirow{2}{*}{ No. of doses } & IV & Labetalol & \multicolumn{2}{c|}{ Oral Nifedipine } \\
\cline { 2 - 5 } & No. & $\mathbf{\%}$ & No. & $\mathbf{\%}$ \\
\hline 1 & 6 & 15 & 22 & 55 \\
\hline 2 & 24 & 60 & 16 & 40 \\
\hline 3 & 8 & 20 & 2 & 5 \\
\hline 4 & 2 & 5 & 0 & 0 \\
\hline 5 & 0 & 0 & 0 & 0 \\
\hline Total & 40 & 100 & 40 & 100 \\
\hline
\end{tabular}

Table 6: Comparison of time taken to control BP between two groups, i.e. to achieve BP $140 / 90 \mathrm{~mm}$ of Hg.

\begin{tabular}{|c|c|c|c|}
\hline Variables & $\begin{array}{l}\text { Labetalol } \\
(\mathrm{n}=40) \\
\text { Mean } \pm \text { SD }\end{array}$ & $\begin{array}{l}\text { Nifedipine } \\
(n=40) \\
\text { Mean } \pm S D\end{array}$ & $\begin{array}{l}\mathbf{P} \\
\text { value }\end{array}$ \\
\hline $\begin{array}{l}\text { Total } \\
\text { antihypertensive } \\
\text { doses (mg) } \\
\text { requires to } \\
\text { achieve BP } \\
140 / 90 \mathrm{~mm} \text { of } \mathrm{Hg}\end{array}$ & $45.00 \pm 17.97$ & $12.63 \pm 2.99$ & 0.0001 \\
\hline
\end{tabular}

Table 6 shows comparison of time taken to control BP between two groups, i.e. to achieve BP 140/90mm of $\mathrm{Hg}$. The mean time required was $43 \pm 14.71$ minutes in IV Labetalol groups and 28 \pm 10.90 minutes in Oral Nifedipine group. This comparison of time showed significant difference in the two groups with a ' $\mathrm{P}$ ' value of 0.0001 . The results of studies conducted mean time required for IV Labetalol and oral Nifedipine to achieve BP 140/90 mm hg in severe pre-eclampsia in Raheem et al was 45 and 30 minutes, Shekhar et al was 60 and 40 minutes, respectively. While in Swapan et al was 47.2 minutes and 45.6 minutes. ${ }^{14,16}$ Hence time required to control raised blood pressure is less with oral Nifedipine as compared with IV Labetalol.

Table 8 shows mode of delivery of the two groups. Vaginal delivery rate in the IV Labetalol group $62.5 \%$ while in oral Nifedipine $65 \%$. Caesareans section rate was $37.5 \%$ and $35 \%$ in the IV Labetalol and oral Nifedipine group respectively. The $\mathrm{P}$ value derived is 0.816 there is so significant difference between two groups but in present study more Vaginal deliveries rates as compared with Ceasrean Section. In studies done by Raheem et al, Shekhar et al and Swapan et al the percentage of vaginal delivery and caesarean section in IV Labetalol group was $48 \%$ and $52 \%, 66.6 \%$ and $33.3 \%, 54 \%$ and $46 \%$ while in oral Nifedipine $36 \%$ and $64 \%, 56.6 \%$ and $43.3 \%, 46 \%$ and $54 \%$ respectively. ${ }^{14-16}$ In this study and in Shekhar et al, caesarean section rates were low, which may be due to better management by antihypertensive agents and low dose of Nifedipine required as it has tocolytic effect in large dose. ${ }^{14,16}$

Table 7: Comparison of total antihypertensive doses required to control $\mathrm{BP}$ between two groups, i.e. to achieve BP 140/90mm of $\mathrm{Hg}$.

\begin{tabular}{|llll|}
\hline Variables & $\begin{array}{l}\text { IV } \\
\text { Labetalol } \\
(\mathrm{n}=40) \\
\text { Mean } \pm \text { SD }\end{array}$ & $\begin{array}{l}\text { Oral } \\
\text { Nifedipine } \\
(\mathrm{n}=40) \\
\text { Mean } \pm \text { SD }\end{array}$ & $\begin{array}{l}\text { P } \\
\text { value }\end{array}$ \\
$\begin{array}{l}\text { Total } \\
\text { antihypertensive } \\
\text { dosage (mg) } \\
\text { requires to } \\
\text { achieve BP }\end{array}$ & $45.00 \pm 17.97$ & $12.63 \pm 2.99$ & 0.0001 \\
$140 / 90 \mathrm{~mm}$ of $\mathrm{Hg}$ & & & \\
\hline
\end{tabular}

Table 8: Mode of delivery of two groups.

\begin{tabular}{|c|c|c|c|c|c|}
\hline \multirow{2}{*}{$\begin{array}{l}\text { Mode of } \\
\text { delivery }\end{array}$} & \multicolumn{2}{|c|}{ IV Labetalol } & \multicolumn{2}{|c|}{ Oral Nifedipine } & \multirow{2}{*}{$\begin{array}{l}\mathbf{P} \\
\text { value }\end{array}$} \\
\hline & No. & $\%$ & No. & $\%$ & \\
\hline $\begin{array}{l}\text { Vaginal } \\
\text { delivery }\end{array}$ & 30 & 62.5 & 26 & 65 & \multirow{3}{*}{0.816} \\
\hline LSCS & 10 & 37.5 & 14 & 35 & \\
\hline Total & 40 & 100 & 40 & 100 & \\
\hline
\end{tabular}

Table 9 shows Hyperbilirubinemia were 5\% and $2.5 \%$ in the Labetalol group and Nifedipine group respectively. Respiratory distress neonates were $2.5 \%$ in each Labetalol and Nifedipine group. There was 5\% neonatal admission due to meconium aspiration in the IV Labetalol group and $2.5 \%$ in oral Nifedipine group.

In the present study birth asphyxia and meconium aspiration mostly seen in patients with blood pressure $\geq 180 / 110$ and required more dosages $\geq 3$ to control blood 
pressure in both the groups while hyperbilirubinemia is not related to it.

Table 9: Comparison of indications of neonatal admission in NICU between two groups.

\begin{tabular}{|lll|} 
Variables & $\begin{array}{l}\text { IV Labetalol } \\
(\%)(\mathbf{n = 4 0 )}\end{array}$ & $\begin{array}{l}\text { Oral } \\
\text { Nifedipine } \\
(\%)(\mathbf{n}=40)\end{array}$ \\
\hline Hyperbilirubinemia & $2(5 \%)$ & $1(2.5 \%)$ \\
\hline Respiratory distress & $1(2.5 \%)$ & $1(2.5 \%)$ \\
\hline Meconium aspiration & $2(5 \%)$ & $1(2.5 \%)$ \\
\hline Birth asphyxia & $2(5 \%)$ & $0(0 \%)$ \\
\hline
\end{tabular}

Table 10 shows the comparison of adverse effects of the drugs. $2.5 \%$ patients had headache in each group. In the IV Labetalol group $2.5 \%$ of the patients had postural hypotension, $5 \%$ of had drowsiness and $17.5 \%$ had palpitations. Adverse effects occurred during treatment with antihypertensive agents, were transient and tolerable. There were no maternal adverse events, which resulted in need for discontinuation of medication.

Table 10: Comparison of adverse effects of drugs between two groups.

\begin{tabular}{|lll|}
\hline Adverse effects & $\begin{array}{l}\text { IV } \\
\text { Labetalol }\end{array}$ & $\begin{array}{l}\text { Oral } \\
\text { Nifedipine }\end{array}$ \\
\hline Postural hypotension & 1 & 0 \\
\hline Drowsiness & 2 & 0 \\
\hline Headache & 1 & 1 \\
\hline Palpitation & 7 & 0 \\
\hline Depression & 0 & 0 \\
\hline Nausea & 0 & 0 \\
\hline Hypersensitivity & 0 & 0 \\
\hline Total & 11 & 1 \\
\hline
\end{tabular}

\section{DISCUSSION}

Pregnancy induced hypertension or Pre-eclampsia is one of the common medical disorders of pregnancy. It complicates 6 to $8 \%$ of pregnancies and is the third common cause for maternal mortality and morbidity next to haemorrhage and infections. ${ }^{13,2} 18 \%$ of maternal deaths are due to pregnancy related hypertension complications. It affects both mother and fetus. ${ }^{7-9}$ Hypertension during pregnancy predisposes to complications like eclampsia, Abruptio placentae, disseminated intravascular coagulation, pulmonary oedema, blindness, cerebrovascular haemorrhages, HELLP syndrome, fetal growth restriction and fetal demise. Controlling hypertension in pregnancy prevents complications both in mother and fetus.

There are various theories for the aetiology of pregnancy induced hypertension. The common pathophysiological changes seen are imbalance between vasoconstrictor Thromboxane and vasodilator prostacyclin resulting in generalized vasospasm. This leads to endothelial damage resulting in release of vasoactive substances. This causes decreased intravascular volume and increased extravascular volume. The effects of this are placental insufficiency resulting in complications..$^{6-9}$

Controlling hypertension in pregnancy using antihypertensive drugs brings down these complications. The most extensively used antihypertensive drugs in pregnancy are $\beta$ adrenoceptor antagonists, Nifedipine, methyldopa and Labetalol. ${ }^{13}$ These drugs are used alone or in combinations in routine obstetric practice in our country. Each of these drugs have different mode of action. Nifedipine is vasodilator and calcium channel blocker. Methyl dopa is centrally acting antihypertensive. Labetalol is both $\alpha$ and $\beta$ blocker. There were few clinical studies in which these drugs were compared in the same setting, when used orally with respect to their antihypertensive efficacy, side effects, maternal and neonatal outcome both in mild and severe PIH. Therefore, the present study was undertaken to evaluate and compare nifedipine and labetalol in mild and severe PIH.

For this study pregnant women fulfilling the definition of pregnancy induced hypertension, inclusion and exclusion criteria were enrolled. They were divided into two groups based on antihypertensive drugs used. Base line characters efficacy, maternal and neonatal outcomes were analysed separately in two treatment groups of PIH patients.

\section{CONCLUSION}

A hypertensive disorder of pregnancy is one of the lifethreatening complication encountered in obstetrics and globally is major cause of maternal morbidity and mortality. Management of acute severe Hypertension in pregnancy is a challenging task, because drastic reduction of BP leads to uteroplacental insufficiency and that may lead to intrauterine fetal death and continuation of pregnancy with severe hypertension leads to adverse fetomaternal outcome. Therefore, there is a need for an ideal antihypertensive agent for effective control of severe hypertension in pregnancy.

Present study compares the efficacy of oral Nifedipine and IV Labetalol in reaching the therapeutic goal. From the results of our study we can well conclude that oral Nifedipine is more efficacious is at variance with results of previously conducted trial with (similar design) that both drugs are equally efficacious. Although we have tried to analyse almost all the possible factors it would be prudent to say that more analyses and large sample are required to derive the definite conclusions regarding difference in effectiveness of oral Nifedipine as compared with IV Labetalol and to assess this difference clinically significant.

Nevertheless, these results do establish oral Nifedipine as an alternative to IV Labetalol in lowering BP in Acute Severe Hypertension. In summary oral Nifedipine may be preferable as it has a convenient dosing pattern orally. 
Funding: No funding sources

Conflict of interest: None declared

Ethical approval: The study was approved by the Institutional Ethics Committee

\section{REFERENCES}

1. Naden RP, Redman CW. Antihypertensive drugs in pregnancy. Clin Pernatol. 1985;12(3):521-38.

2. Ferrao MH, Pereira AC, Gersgorin HC, Paula TA, Correa RR, Castro EC. Treatment effectiveness of hypertension during pregnancy. Rev Assoc Med Bras. 2006;52(6):390-4.

3. Fabry IG, Richart T, Chengz X, Bortel VLM, Staaessen JA. Diagnosis and treatment of hypertensive disorders during pregnancy. Act Clin Belg. 2010;65(4):229-36.

4. Ray JG, Vermeculen M, Burrows E, Burrows R. Use of antihypertensive medication in pregnancy and the risk of adverse perinatal outcomes: McMaster outcome study of hypertension in pregnancy 2 (MOS HIP 2). BMC Pregnancy Childbirth. 2001;1:6-14.

5. Nakhai-Pour HR, Rey E, Berard A. Antihypertensive medication use during pregnancy and the risk of major congenital malformation or small-forgestational-age newborns. Birth Defects Res B Dev Reprod Toxicol. 2010;89(2):147-54.

6. Granger JP, Alexander BT, Bennett WA, Khalil RA. Pathophysiology of pregnancy-induced hypertension. Am J Hypertens. 2001;14(6):178S-85S.

7. Granger JP, Alexander BT, Llinas MT, Bennett WA, Khalil RA. Pathophysiology of hypertension during preeclampsia linking placental ischemia with endothelial dysfunction. Hypertension. 2001;38(3):718-22.

8. Haram K, Biorge L, Guttu K. Pathophysiology and clinical manifestations in pre-eclampsia. Tidsskr Nor Laegeforen. 2000;120(12):1426-31.
9. Chandiramani M, Joash K, Shennan AH. Options and decisionmaking: hypertensive disorders of pregnancy. Future Cardiol. 2010;6(4):535-46.

10. Witlin AG, Sibai BM. Magnesium sulphate therapy in preeclampsia and eclampsia. Obstet Gynecol. 1998;92:883-9.

11. Podymow T, August P. Update on the use of antihypertensive drugs in Pregnancy. Hypertension J Am Heart Assoc. 2008;51(4):960-9.

12. Magee LA, Helewa M, Rey E. Diagnosis, Evaluation, and management of the hypertensive disorders of pregnancy. JOGC. 2008;30(3)(1):S1-2.

13. Ghanem FA, Movahed A. Use of antihypertensive drugs during pregnancy and lactation. Cardiovasc Ther. 2008;26(1):38-49.

14. Raheem IA, Saaid R, Omar SZ, Tan PC. Oral nifedipine versus intravenous labetalol for acute blood pressure control in hypertensive emergencies of pregnancy: a randomised trial. BJOG. 2012;119(1):78-85.

15. Shekhar S, Sharma C, Thakur S, Verma S. Oral Nifedipine or Intravenous Labetalol for hypertensive emergency in pregnancy: a randomized controlled trial. Obstet Gynecol. 2013;122(5):1057-63.

16. Swapan D, Swagata B, Prakash D, Biswajit M. Comparative study of intravenous Labetalol and oral Nifedipine for control of blood pressure in severe preeclampsia. IOSR J Dental Med Sci. 2015;14(10):22-7.

Cite this article as: Gavit Y, Sharma D, Dixit PV. A comparative study of oral nifedipine and intravenous labetalol in control of acute hypertension in severe pre-eclampsia and eclampsia. Int J Reprod Contracept Obstet Gynecol 2018;7:719-24. 